\title{
Heat and mortality in New York City since the beginning of the 20th century
}

\author{
Elisaveta P. Petkova ${ }^{1}$, Antonio Gasparrini ${ }^{2}$, and Patrick L. Kinney ${ }^{1, *}$ \\ ${ }^{1}$ Department of Environmental Health Sciences, Mailman School of Public Health, Columbia \\ University, 722 West 168th St., New York, NY 10032, USA \\ ${ }^{2}$ Department of Medical Statistics, London School of Hygiene and Tropical Medicine, Keppel \\ Street WC1E 7HT London, UK
}

\section{Abstract}

Background-Heat is recognized as one of the deadliest weather-related phenomena. Although the impact of high temperatures on mortality has been a subject of extensive research, few previous studies have assessed the impact of population adaptation to heat.

Methods-We examined adaptation patterns by analyzing daily temperature and mortality data spanning more than a century in New York City. Using a distributed-lag non linear model, we analyzed the heat-mortality relationship in adults age 15 years or older in New York City during two periods: 1900 to 1948 and 1973 to 2006, in order to quantify population adaptation to high temperatures over time.

Results-During the first half of the century, the decade-specific relative risk of mortality at 29 ${ }^{\circ} \mathrm{C}$ vs. $22{ }^{\circ} \mathrm{C}$ ranged from 1.30 (95\% confidence interval $=1.25$ to 1.36 ) in the 1910 s to 1.43 (1.37 to 1.49 ) in the 1900s. Since the 1970s, however, there was a gradual and substantial decline in the relative risk, from 1.26 (1.22 to 1.29) in the 1970s to 1.09 (1.05 to 1.12) in the 2000s. Age-specific analyses indicated a greater risk for people age 65 years and older in the first part of the century but there was less evidence for enhanced risk among this older age group in more recent decades.

Conclusion-The excess mortality with high temperatures observed between 1900 and 1948 was substantially reduced between 1973 and 2006, indicating population adaption to heat in recent decades. These findings may have implications for projecting future impacts of climate change on mortality.

Heat-related mortality has become a research topic of increasing importance as a result of increases in average temperature - as well as temperature extremes - due to climate change.

\footnotetext{
*Correspondence: Patrick L. Kinney, Department of Environmental Health Sciences, Mailman School of Public Health, Columbia University, 722 West 168th St., New York, NY 10032, USA, plk3@ columbia.edu, Phone: +001 (212) 305-3663, Fax: +001 (212) 305-4012.

epp2109@columia.edu (Petkova), antonio.gasparrini@1shtm.ac.uk, Phone: +44 (0)20 79272406

SDC Supplemental digital content is available through direct URL citations in the HTML and PDF versions of this article (www.epidem.com). This content is not peer-reviewed or copy-edited; it is the sole responsibility of the author.

This is a PDF file of an unedited manuscript that has been accepted for publication. As a service to our customers we are providing this early version of the manuscript. The manuscript will undergo copyediting, typesetting, and review of the resulting proof before it is published in its final citable form. Please note that during the production process errors may be discovered which could affect the content, and all legal disclaimers that apply to the journal pertain.
} 
Since the early 2000s, and particularly after the 2003 European heat wave,,${ }^{1-3}$ multiple studies have been carried out to characterize temperature effects in various locations. ${ }^{4-9}$ These studies have found J-shaped or U-shaped temperature-mortality relationships, depending on the location. Some studies have limited the analysis to the summer months in order to focus on heat effects.

In a literature review, Basu ${ }^{10}$ concluded that temperature has an independent effect on mortality and that the confounding effects of particulate matter and ozone are relatively small. In addition to their effects on mortality, heat extremes affect health in other ways. For example, high temperatures have been associated with increases in hospitalizations and emergency room visits. ${ }^{11-14}$ The leading risk factors for heat-induced morbidity and mortality are very young or old age, pre-existing medical conditions, social isolation, and poverty. ${ }^{10,15-17}$ In western societies including the United States, people aged 65 and over are the most vulnerable to heat-related mortality. $5,18,19$

Daily mortality data are rarely available before the 1960s. A better understanding of the historical impact of temperature on mortality may provide valuable insights about historical patterns of population adaptation to high temperatures and improve methods for projecting heat-related deaths into the future. Carson and colleagues ${ }^{20}$ reported a weakening of temperature effects on cold- and heat-related mortality in London, United Kingdom in the course of the $20^{\text {th }}$ century. Their study used weekly mortality data, making interpretation with respect to daily effects challenging. Ekamper and colleagues ${ }^{21}$ analyzed 150 years of daily temperature-related mortality in the Netherlands in 25-year increments and reported a reduction in the heat effect since the 1930-1954 period. A recent study by Åström and colleagues $^{22}$ of 110 years of daily mortality and temperature data in Stockholm County, Sweden found a similarly declining trend in heat-related mortality over time. The declining trend appears to have plateaued in recent decades.

We address this issue by characterizing the relationship between daily summer-time temperature and mortality since 1900 in New York City. New York City is particularly susceptible to the effects of high temperatures due its dense population, including many vulnerable residents. ${ }^{23}$

Heat has been recognized as a public health hazard in New York City for over a century. In 1896, after a prolonged heat wave, over 1500 people were reported to have died in the city. ${ }^{24}$ Dating back to this time are some of the earliest city efforts to prevent the impacts of heat, particularly among vulnerable populations. During the 1896 heat wave, Theodore Roosevelt, a mayoral candidate at the time, championed the distribution of free ice to the poorest communities of New York City. ${ }^{24}$ Today, the city has implemented various citylevel measures during heat-wave episodes, such as heat warning systems and cooling centers.

The study of weather-related phenomena on daily mortality in New York City was pioneered by Ellworth Huntington in the beginning of last century. In "Civilization and Climate", Huntington hypothesized that climatic conditions, such as temperature and humidity have physiologically optimal levels, and that maintaining these levels may 
improve morbidity and mortality. ${ }^{25}$ In a subsequent analysis of daily mortality data for New York City data between 1882 and 1888, Huntington and Justin found that mortality increased rapidly as temperatures rose above $63^{\circ} \mathrm{F} .{ }^{26,27}$

The mortality effects of high temperatures in New York City did not become a subject of rigorous study until the 1970s. At that time, several studies investigated the possible impact of air conditioning on heat-wave mortality across the United States. Marmor ${ }^{28}$ investigated ratios of predicted-to-observed heat-wave mortality during 12 summers between 1949 and 1970 in New York City. This period was selected for study because air conditioning ownership in the city had increased from virtually zero in 1949 to $14 \%$ in 1960 and $38 \%$ in 1970. The study reported decreasing excess mortality during early-summer heat-waves but no similar change in excess mortality during heat waves occurring later in the summer. ${ }^{28}$

Davis and colleagues ${ }^{8}$ examined decadal changes in summer weather-mortality relationships for 28 U.S. cities between 1964 and 1998 and found an overall decline in mortality on hot and humid days. For New York City, the mortality increase with temperatures above an apparent-temperature threshold of $30^{\circ} \mathrm{C}$ was greater in the 1960s and 1970s than in the 1990 s. $^{8}$ However, in a study of year-round weather-related mortality in eastern U.S. cities (including New York City) by Curriero and colleagues, ${ }^{7}$ the relationship between weather and mortality from 1973 to 1994 was found to be quantitatively similar to that for four shorter periods within the same time frame. Comparison of findings across studies is challenging due to the utilization of different modeling approaches.

We first present a historical analysis of the heat-mortality relationship in New York City from 1900 to 1948, and compare it with the more recent period of 1973 to 2006. Next, we investigate how the heat-mortality response has changed over time in both periods, reflecting possible population adaptation. We discuss probable underlying mechanisms of adaptation to heat in New York City, and the implications for modeling future effects of high temperatures on mortality.

\section{Methods}

\section{Mortality Data}

1900-1948 —Death records prior to 1949 are stored at the New York City Department of Records and Information Services. Death records for later years are stored at the New York City Department of Health and Mental Hygiene and were not directly accessible or available in digital format. Death indexes, including each documented death in the five New York City boroughs (Bronx, Brooklyn, Manhattan, Queens, and Staten Island) from 1900 to 1948, were scanned by the Genealogy Federation of Long Island. Scanned records were entered into an electronic spreadsheet and subsequently proofread and edited to ensure accuracy. Each death record contains day, month, year, borough and person's age at death. Age information recorded in various formats in the original death certificate (e.g. $501 \frac{1}{2}$ years, $3 / 4$ months, stillborn) was converted into integers rounded to the lower value. Records containing ambiguous information (such as unrealistic values for date or age) and spelling errors (such as extra symbols or spaces) were eliminated. Records containing missing values were also eliminated. Altogether, fewer than $0.5 \%$ of the records were eliminated. 
Annual numbers of deaths from these records were compared with the numbers published in the New York City Department of Health's annual Summary of Vital Statistics reports. Annual data after 1936 were available from the New York City Department of Health website. ${ }^{29}$ Annual data prior to 1936 were obtained directly from the Bureau of Vital Statistics (eTable 1). Annual calculated numbers of deaths were between $0.02 \%$ and $4.94 \%$ (median $0.95 \%$ ) higher than those reported. The number of deaths that occurred during welldocumented events (such as the PS General Slocum fire of 15 June 1904, the Triangle Fire of 25 March 1911 and the 1918 flu epidemics) are consistent with reported data.

1973-2006-Daily multiple-cause-of-death mortality data for 1973-2006 were obtained in collaboration with Joel Schwartz and colleagues at Harvard University School of Public Health from the U.S. National Center for Health Statistics. The dataset contains daily death counts for all five New York City boroughs.

\section{Temperature Data}

We obtained daily temperature data for the New York Central Park station from 1973 onwards from the National Climatic Data Center. Daily temperature data before 1949, also for New York Central Park, were obtained from the United States Historical Climatology Network. There were five missing records in the data prior to 1949 that were substituted with the averages of the previous and following day temperatures.

\section{Analysis of temperature-mortality relationships}

We characterized the temperature-mortality relationships for each period using the distributed-lag non-linear model module in R. ${ }^{30}$ Distributed-lag non-linear models allow a simultaneous characterization of the non-linear and lagged effects of temperature on mortality. ${ }^{31,32}$ The temperature-mortality analysis was restricted to the summer months (June to September) because we wanted to focus on heat-related mortality. Also, the cause of death was not available in our data, and we were unable to account for influenza deaths during the winter months. We limited the analysis to adults ( 15 years or older) and derived models using the total number of deaths, as well as, deaths for three age groups: 15-44, $45-64$, and 65 years and older. Note that since life expectancy was shorter at the beginning of the century, the number of deaths in individuals 75 years and over was very small. Data were analyzed by decade: 1900-1909 (1900s), 1910-1919 (1910s), 1920-1929 (1920s), 1930-1939 (1930s), 1940-1948 (1940s), 1973-1979 (1970s), 1980-1989 (1980s), 1990-1999 (1990s) and 2000-2006 (2000s).

We developed the decadal models using mean daily temperature and $22{ }^{\circ} \mathrm{C}$ (corresponding to approximately the 80th percentile of annual temperature) as a reference temperature for calculating relative risk. Fixed temperatures, rather than decade-specific percentiles, were used in estimating temperature effects because this approach allowed comparisons of the impact of an identical temperature exposure on mortality over time. Preliminary analyses indicated that results were not affected substantially if decade-specific percentiles were used. The models were fitted using a quadratic spline with 4 degrees of freedom (two equally spaced knots) for temperature and a natural spline with 4 degrees of freedom for the lag, and controlling for seasonal and day-of-week effects. Quadratic spines have the 
advantage of not being constrained at the boundaries and thus are flexible enough to capture mortality effects at the highest temperatures. ${ }^{33}$ We considered lag durations between 3 days and 10 days to explore possible changes in the lag structure over time; a lag of 5 days was selected for the main model. We also tested models with both quadratic and natural cubic splines and found that the Akaike's Information Criterion for quasi-Poisson models (Q-AIC) was consistently lower for models with quadratic splines. In sensitivity analyses, we fitted models with quadratic splines ranging from 4 to 6 degrees of freedom for the temperature and from 3 to 5 degrees of freedom for the lag. We considered this amount of smoothing sufficient to capture the underlying non-linear relationship. We controlled for seasonal cycles using a natural spline with 2 degrees of freedom per year, and we controlled for within-summer seasonal variation using a natural spline with 4 degrees of freedom for day in year. ${ }^{33,34}$ The decadal cumulative relative risk estimates at $29^{\circ} \mathrm{C}$ (corresponding to approximately the 99th percentile of mean daily temperature) were chosen as a marker of the heat effect. To test for the difference in the effect of heat on mortality over time, we carried out univariate random-effects meta-regression estimated by restricted maximum likelihood. ${ }^{35}$ The $\mathrm{R}$ code for the main analysis is provided in the eAppendix.

\section{Results}

Summary temperature statistics and population data ${ }^{36,37}$ for New York City during the study time periods are presented in Table 1 and eFigure 1, respectively.

Previous studies have reported that the seasonality of mortality has changed substantially over time. In Japan, for example, peak mortality has shifted in the course of a century from summer to winter months. ${ }^{38}$ We did not observe a similar transition in New York City. The seasonality of mortality in New York City was similar for each decade since the 1900s (results not shown), but with peak mortality between January and April in the beginning of the century and between December and March in more recent years. This slight shift in seasonal peak is controlled for in our analysis by using different models for each decade, each of which can flexibly control for seasonal effects on mortality.

The non-linear distributed-lag models showed a similar relationship between temperature and mortality for all periods. Decadal temperature-mortality curves of overall cumulative risk are presented on Figure 1. The heat effect was much more pronounced in the first five decades. For the most recent decades, the temperature effect was highest in the 1970s and diminished across the next three decades. The lag structure (Figure 2) also changed over time. During the first half of the century, we observed a partial harvesting effect immediately after the substantial increase in mortality in the first days following heat exposure. The harvesting effect was particularly pronounced during the 1910s. Nonetheless, the heat effect was only partially compensated for by harvesting. Decade-specific temperature-mortality curves and lag structure charts are presented in Figures 2 and 3, respectively.

To summarize the change in the temperature effect over time, we plotted cumulative relative risk estimates at $29^{\circ} \mathrm{C}$ (Figure 3) versus the reference temperature of $22^{\circ} \mathrm{C}$. As the plot illustrates, there was no evidence of adaptation during the first half of the century. Relative 
risks fluctuated between 1.30 (95\% confidence interval $[\mathrm{CI}]=1.25-1.36)$ in the 1910 s to 1.43 (1.37-1.49) in the 1900s during this period. The random-effects meta-regression (including a binary indicator for period) showed strong evidence of a difference between the first and the second part of the century. Predicted average relative risks were 1.38 (1.31-1.44) for the period between 1900-1948 and 1.15 (1.09-1.2) for 1973-2006. Since the 1970s, there has been a gradual decline in the relative risk, indicating population adaptation to heat. The random-effects meta-regression including a linear term for decade estimated a decrease of $4.6 \%(95 \% \mathrm{CI}=2.4 \%-6.7 \%)$ per decade.

Results from the age-specific analyses are presented in Table 2. During the first part of the century, the temperature effect was most substantial for the oldest age group (age 65 years and older). More homogeneous and consistently decreasing risk is indicated in the second part of the century. By the 1980s there is less evidence of excess mortality among the oldest group. Age-specific temperature-mortality curves and lag structures are displayed in the eFigures 4 - 9 .

Results from the sensitivity analysis for the temperature effect along with Akaike's Information Criterion for quasi-Poisson values for each alternative model are presented in the eTables 2 and 3. Estimates were robust to alternative modeling choices, except for the 1900s. The differences across models for this decade are due to the 1901 heat wave, which was the deadliest in New York City during our study period.

\section{Discussion}

Heat-related mortality has taken on increasing relevance in recent years with widespread increases in average temperatures - as well as temperature extremes - due to climate change. Our analysis of daily mortality in New York City between 1900 and 1948 and between 1973 and 2006 provides historical insights about the summer temperature-mortality response since the beginning of the $20^{\text {th }}$ century.

Using non-linear distributed lag models to characterize the overall relationship between temperature and mortality during the five decades between 1900 and 1948 and the four decades between 1973 and 2006, we observed more pronounced heat effects in the first five decades. Many factors may underlie the substantial heat effect in the first half of the $20^{\text {th }}$ century. Housing conditions, especially in New York City's immigrant communities, were particularly poor in the beginning of the century. During this period, many immigrants settled in tenement buildings or in multifamily dwellings with one or two rooms per family. Many tenements had no windows. Although the Tenement House Act of 1867 required tenements to meet basic sanitary and health standards, few improvements were introduced until the 1920s. Many tenements were not replaced with modern buildings until several decades later. Ice and cold liquids were among the primary means for alleviating heat stress at the time, but these were not widely accessible in the early part of the century. Commercial refrigerators were not introduced until 1915, and they were not common until the 1930s. Even with technological and lifestyle improvements during the first part of the $20^{\text {th }}$ century, the population sensitivity to heat did not decline. 
The successful adaptation to heat in the second part of the century may be due largely to increased use of air conditioning. By the 1970s, the heat effect had started to decline as air conditioning prevalence increased. Individual room air conditioning became available in the 1950s and central air conditioning became common in the 1970s. In 1970, 39\% of households surveyed in the NYC metropolitan area had air conditioning, and fewer than $4 \%$ of them had central air conditioning. ${ }^{39}$ By $2003,84 \%$ of surveyed households had air conditioning, and $16 \%$ had central air conditioning. ${ }^{40}$ These findings suggest that access to comfortable indoor environments, particularly during the hottest days, may be the most important factor in the decline in heat-related mortality. The introduction in more recent years of heat-warning systems and of cooling centers may also have contributed to decreasing vulnerability.

As expected, the temperature effect was most substantial in the oldest age group during most decades. Temperature effects have declined substantially since the beginning of the century in all age groups, and the decline has been particularly pronounced in persons age 65 or older. The substantial decrease in heat sensitivity among older people may reflect improvements in overall health, and perhaps a greater awareness of the risks presented by exposure to high temperatures.

We also observed a change in the lag structure of the temperature effect over time. The harvesting effect that was evident during the first couple of days after exposure in the early part of the century may indicate more deaths among the most susceptible persons who did not have access to any form of relief from the heat.

One limitation of our study is that we were unable to adjust for any measure of air pollution. In addition, since we did not have information on the underlying causes of death, we were unable to investigate how changing disease patterns (such as the substantial decline in cardiovascular mortality) might have influenced trends in heat-related mortality.

This work has several important implications for projecting future mortality effects of climate change. First, historical trends may not accurately predict future risk. For example, using the estimates from the 1970s to project mortality in the 2000s would have substantially overestimated heat effects. A recent review found that half of the studies projecting heat-related mortality under various climate-change scenarios have based projections on historical relationships without consideration of heat adaptation. ${ }^{41}$ Models for future mortality should take into account changing risks that relate to adaptation processes, including the increased availability of air conditioning. ${ }^{23}$ Second, despite the diminished sensitivity to heat over time, the temperature-mortality curves for New York City have maintained a similar shape throughout the century. This should be taken into account in projecting future temperature effects. Finally, historical data may be useful in projecting possible effects of heat (and, in particular, heat waves) in the event of future power outages or natural disasters, during which the population may lose access to air conditioning for extended periods.

In conclusion, we examined the relationship between summer daily temperature and mortality since the beginning of the $20^{\text {th }}$ century. Heat effects were more pronounced in the 
first five decades, despite substantial technological and lifestyle improvements in New York City during the first part of the 20th century. We also found evidence of a short-term harvesting effect in the first part of the century, which partially offset the substantial heat effects during this period. In contrast, there has been a substantial decrease of the heat effect since the 1970s, which may reflect the rapid spread and widespread availability of air conditioning.

To our knowledge, this study was the first to examine daily temperature effects in any large U.S. city over a period spanning more than a century, using modern statistical methods. Our findings can potentially have important implications for projecting future mortality impacts of climate change.

\section{Supplementary Material}

Refer to Web version on PubMed Central for supplementary material.

\section{Acknowledgments}

We thank Professor Joel Schwartz and Antonella Zanobetti from the Harvard School of Public Health for providing daily mortality data. We also thank John Martino from the Genealogy Federation of Long Island for providing historical daily mortality data.

Sources of financial support: This work was supported by the Consortium for Climate Risk in the Urban Northeast (CCRUN), NIEHS Center grant ES009089 (Elisaveta P. Petkova and Patrick L. Kinney) and a Methodology Research fellowship from Medical Research Council-UK (grant ID G1002296) (Antonio Gasparrini)

\section{References}

1. Bouchama A. The 2003 European heat wave. Intensive Care Med. 2004; 30:1-3. [PubMed: 14716475]

2. Fouillet A, Rey G, Laurent F, et al. Excess mortality related to the August 2003 heat wave in France. Int Arch Occup Environ Health. 2006:16-24. [PubMed: 16523319]

3. Le Tertre A, Lefranc A, Eilstein D, et al. Impact of the 2003 Heat wave on All-Cause Mortality in 9 French Cities. Epidemiology. 2006; 17:75-9. [PubMed: 16357598]

4. Anderson BG, Bell ML. Weather-Related Mortality: How Heat, Cold, and Heat Waves Affect Mortality in the United States. Epidemiology. 2009; 20:205-13. [PubMed: 19194300]

5. Basu R, Dominici F, Samet JM. Temperature and Mortality among the Elderly in the United States: A Comparison of Epidemiologic Methods. Epidemiology. 2005; 16:58-66. [PubMed: 15613946]

6. Braga AL, Zanobetti A, Schwartz J. The effect of weather on respiratory and cardiovascular deaths in 12 U.S. cities. Environmental Health Perspectives. 2002; 110:859-63. [PubMed: 12204818]

7. Curriero FC, Heiner KS, Samet JM, et al. Temperature and Mortality in 11 Cities of the Eastern United States. American Journal of Epidemiology. 2002; 155:80-7. [PubMed: 11772788]

8. Davis RE, Knappenberger PC, Michaels PJ, et al. Changing heat-related mortality in the United States. Environmental Health Perspectives. 2003; 111:1712-8. [PubMed: 14594620]

9. Medina-Ramon M, Zanobetti A, Cavanagh DP, et al. Extreme temperatures and mortality: assessing effect modification by personal characteristics and specific cause of death in a multi-city case-only analysis. Environmental Health Perspectives. 2006; 114:1331-6. [PubMed: 16966084]

10. Basu R. High ambient temperature and mortality: a review of epidemiologic studies from 2001 to 2008. Environmental Health. 2009; 8:40. [PubMed: 19758453]

11. Jones T, Liang AP, Kilbourne EM, et al. Morbidity and mortality associated with the July 1980 heat wave in St Louis and Kansas City, MO. JAMA. 1982; 247:3327-3331. [PubMed: 7087075] 
12. Semenza JC, McCullough JE, Flanders WD, McGeehin MA, Lumpkin JR. Excess hospital admissions during the July 1995 heat wave in Chicago. American Journal of Preventive Medicine. 1999; 16:269-277. [PubMed: 10493281]

13. Knowlton K, Rotkin-Ellman M, King G, Margolis HG, Smith D, Solomon G, Trent R, English P. The 2006 California heat wave: impacts on hospitalizations and emergency department visits. Environ Health Perspect. 2009; 117:61. [PubMed: 19165388]

14. Green R, Basu R, Malig B, Broadwin R, Kim J, Ostro B. The effect of temperature on hospital admissions in nine California counties. International Journal of Public Health. 2010; 55:113-121. [PubMed: 19771392]

15. Kovats RS, Hajat S. Heat stress and public health: a critical review. Annual Review of Public Health. 2008; 29:41-55.

16. Rey G, Fouillet A, Bessemoulin P, et al. Heat exposure and socio-economic vulnerability as synergistic factors in heat-wave-related mortality. European Journal of Epidemiology. 2009; 24:495-502. [PubMed: 19642001]

17. Vandentorren S, Bretin P, Zeghnoun A, et al. August 2003 Heat Wave in France: Risk Factors for Death of Elderly People Living at Home. The European Journal of Public Health. 2006; 16:58391. [PubMed: 17028103]

18. Kovats RS, Ebi KL. Heat waves and public health in Europe. The European Journal of Public Health. 2006; 16:592-599.

19. Whitman S, Good G, Donoghue ER, et al. Mortality in Chicago attributed to the July 1995 heat wave. American Journal of Public Health. 1997; 87:1515-8. [PubMed: 9314806]

20. Carson C, Hajat S, Armstrong B, et al. Declining Vulnerability to Temperature-related Mortality in London over the 20th Century. American Journal of Epidemiology. 2006; 164:77-84. [PubMed: 16624968]

21. Ekamper P, van Poppel F, van Duin C, et al. 150 Years of temperature-related excess mortality in the Netherlands. Demographic Research. 2009; 21:385-426.

22. Astrom DO, Forsberg B, Edvinsson S, et al. Acute fatal effects of short-lasting extreme temperatures in Stockholm, Sweden: evidence across a century of change. Epidemiology. 2013; 24(6):820-9. [PubMed: 24051892]

23. Kinney P, O'Neill M, Bell M, et al. Approaches for estimating effects of climate change on heatrelated deaths: challenges and opportunities. Environmental Science \& Policy. 2008; 11:87-96.

24. Kohn, EP. Hot Time in the Old Town: The Great Heat Wave of 1896 and the Making of Theodore Roosevelt. Basic Books; 2010.

25. Huntington, E. Civilization and Climate. Yale University Press; New Haven: 1915.

26. Huntington, E. Weather and health: a study of daily mortality in New York City. National Research Council; Washington, DC: 1930.

27. Justin, MM. The Effect of Weather on Health as Shown by a Study of the Mortality Statistics of New York City for the Years 1883-1888. Yale University; 1923.

28. Marmor M. Heat wave mortality in New York City, 1949 to 1970. Archives of Environmental Health. 1975; 30:130-6. [PubMed: 1115538]

29. Summary of Vital Statistics. New York City Department of Health and Mental Hygiene; www.nyc.gov/html/doh/html/pub/pub.shtml?t=vs [Accessed July 1, 2013]

30. Gasparrini A. Distributed Lag Linear and Non-Linear Models in R: The Package dlnm. Journal of statistical software. 2011; 43:1-20. [PubMed: 22003319]

31. Armstrong B. Models for the Relationship between Ambient Temperature and Daily Mortality. Epidemiology. 2006; 17:624-31. [PubMed: 17028505]

32. Gasparrini A, Armstrong B, Kenward MG. Distributed lag non-linear models. Statistics in Medicine. 2010; 29:2224-34. [PubMed: 20812303]

33. Gasparrini A, Armstrong B. The impact of heat waves on mortality. Epidemiology. 2011; 22:6873. [PubMed: 21150355]

34. Hajat S, Armstrong B, Baccini M, et al. Impact of High Temperatures on Mortality: Is There an Added Heat Wave Effect? Epidemiology. 2006; 17:632-8. [PubMed: 17003686] 
35. Van Houwelingen HC, Arends LR, Stijnen T. Advanced methods in meta-analysis: multivariate approach and meta-regression. Statistics in medicine. 2002; 21(4):589-624. [PubMed: 11836738]

36. Gibson, C. Population of the 100 largest cities and other urban places in the United States: 1790 to 1990. U.S. Census Bureau; Washington, D.C.: 1998. Population Division Working Paper No 27

37. U.S. Census Bureau. Census 2000 Data for the State of New York. U.S. Census; [Accessed July 1, 2013]

38. Sakamoto-Momiyama, M. Seasonality in Human Mortality, a Medico-Geographic Study. University of Tokyo Press; Tokyo, Japan: 1977.

39. U.S. Census Bureau. Housing characteristics for selected metropolitan areas. Annual housing survey: 1976. Washington, D.C.: 1978.

40. U.S. Census Bureau. American Housing Survey for the New York-Nassau-Suffolk-Orange Metropolitan Area: 2003. 2004.

41. Huang C, Barnett AG, Wang X, et al. Projecting future heat-related mortality under climate change scenarios: a systematic review. Environmental Health Perspectives. 2011; 119:1681-90. [PubMed: 21816703] 


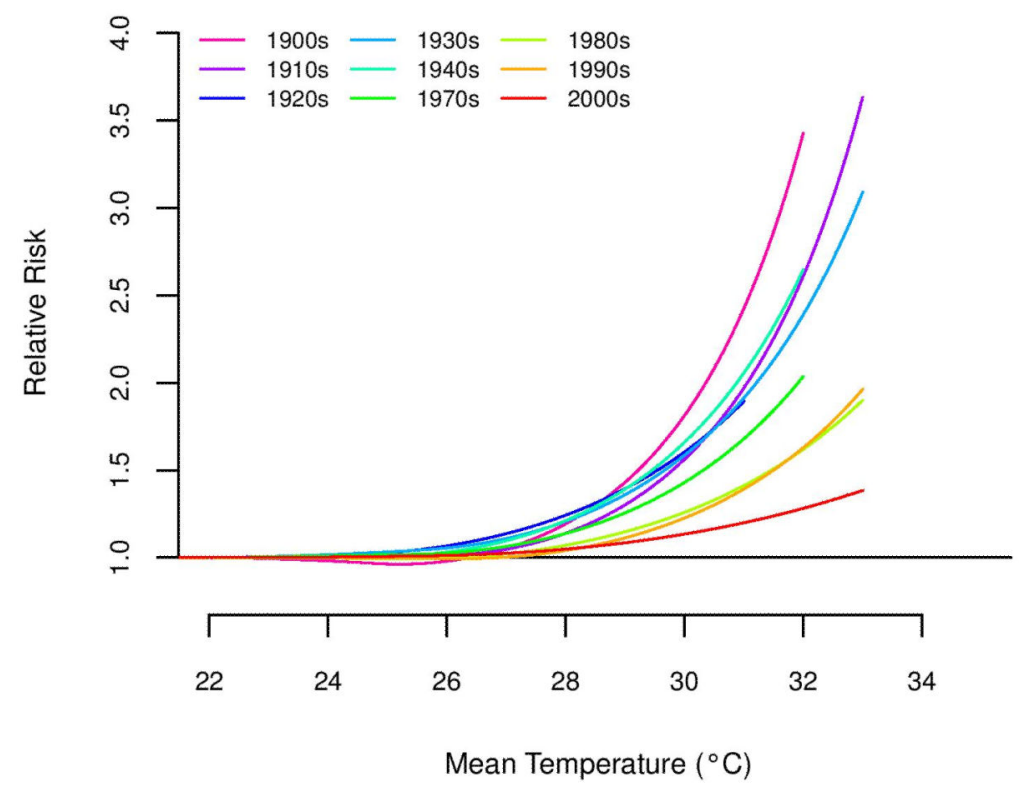

Figure 1.

Temperature - mortality curves of overall cumulative relative risk for New York City by decade, 1900s -2000s. Calculated using a distributed lag non-linear model with a quadratic spline with 4 degrees of freedom for the temperature and a natural cubic spline with 4 degrees of freedom for the lag and $22^{\circ} \mathrm{C}$ as a reference temperature. 


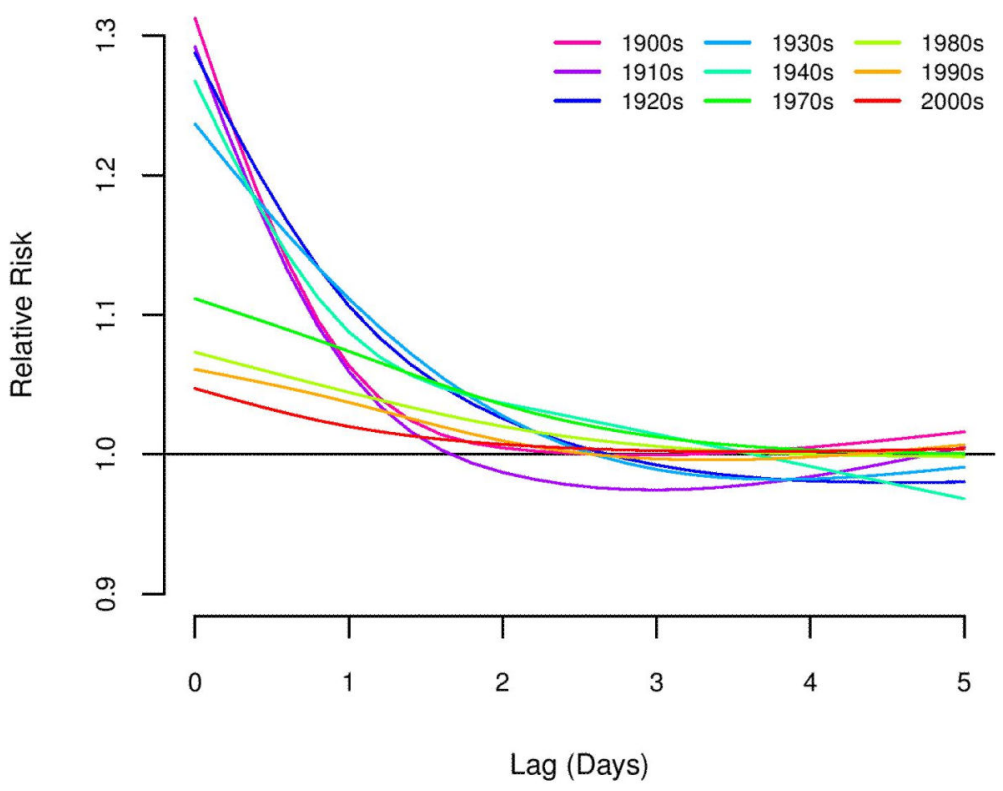

Figure 2.

Lagged relative risks at $29^{\circ} \mathrm{C}$ relative to $22^{\circ} \mathrm{C}$ by decade, $1900 \mathrm{~s}-2000$ s. Calculated using a distributed lag non-linear model with a quadratic spline with 4 degrees of freedom for the temperature and a natural cubic spline with 4 degrees of freedom for the lag. 


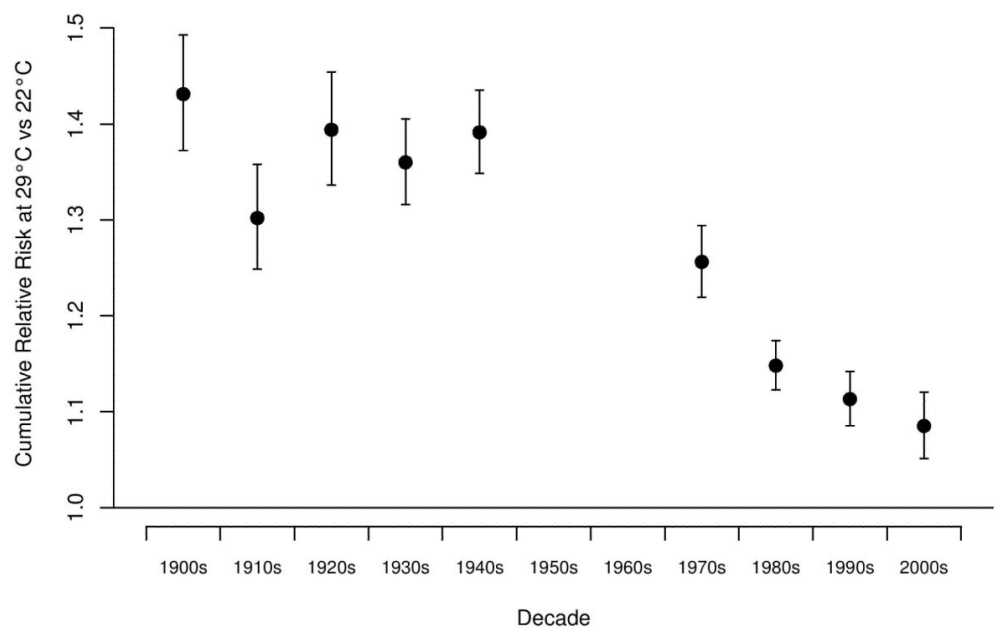

Figure 3.

Overall cumulative relative risk at $29^{\circ} \mathrm{C}$ relative to $22^{\circ} \mathrm{C}$ on mortality in New York City by decade, 1900s-2000s. Calculated using a distributed lag non-linear model with a quadratic spline with 4 degrees of freedom for the temperature and a natural cubic spline with 4 degrees of freedom for the lag. 
Table 1

Temperature $\left({ }^{\circ} \mathrm{C}\right)$ and population statistics for New York City by decade, 1900s-2000s

\begin{tabular}{|c|c|c|c|c|c|}
\hline & \multirow[b]{2}{*}{ Annual mean temperature } & \multicolumn{3}{|c|}{ Percentile of annual mean temperatur } & \multirow[b]{2}{*}{ Population No. } \\
\hline & & $90^{\text {th }}$ & $95^{\text {th }}$ & $99^{\text {th }}$ & \\
\hline 1900s & 11.9 & 25 & 26.4 & 29.2 & $3,437,202$ \\
\hline 1910s & 11.7 & 24.2 & 25.8 & 28.7 & $4,766,883$ \\
\hline 1920s & 11.8 & 23.9 & 25.6 & 28.3 & $5,620,048$ \\
\hline 1930s & 12.5 & 25 & 26.4 & 28.9 & $6,930,446$ \\
\hline $1940 \mathrm{~s}^{a}$ & 12.3 & 25 & 26.4 & 29.2 & $7,454,995$ \\
\hline $1970 \mathrm{~s}^{b}$ & 12.6 & 25 & 26.7 & 29 & $7,894,862$ \\
\hline 1980s & 12.9 & 25.3 & 27.2 & 29.7 & $7,071,639$ \\
\hline 1990s & 13.2 & 25.3 & 26.7 & 29.4 & $7,322,564$ \\
\hline $2000 \mathbf{s}^{c}$ & 13 & 25 & 26.7 & 29.6 & $8,008,278$ \\
\hline
\end{tabular}

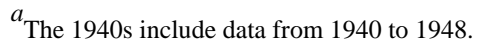

${ }^{b}$ The 1970s include data from 1973 to 1979.

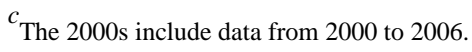




\section{Table 2}

Age-specific overall cumulative relative risk of death at $29^{\circ} \mathrm{C}$ relative to $22^{\circ} \mathrm{C}$ in adults (age 15 years and older) in New York City by decade, 1900s-2000s. Calculated using a distributed lag non-linear model with a quadratic spline with 4 degrees of freedom for the temperature and a natural cubic spline with 4 degrees of freedom for the lag.

\begin{tabular}{|c|c|c|c|c|}
\hline & \multirow{3}{*}{$\begin{array}{c}\text { Total } \\
\text { RR }(95 \% \mathrm{CI})\end{array}$} & \multicolumn{3}{|c|}{ Age (years) } \\
\hline & & $15-44$ & $45-64$ & Over 65 \\
\hline & & RR (95\% CI) & RR $(95 \% \mathrm{CI})$ & RR $(95 \%$ CI) \\
\hline 1900s & $1.43(1.37-1.49)$ & $1.33(1.26-1.40)$ & $1.48(1.39-1.58)$ & $1.57(1.46-1.68)$ \\
\hline 1910s & $1.30(1.25-1.36)$ & $1.25(1.17-1.33)$ & $1.24(1.17-1.32)$ & $1.48(1.38-1.58)$ \\
\hline $1920 \mathrm{~s}$ & $1.39(1.34--1.45)$ & $1.24(1.16-1.33)$ & $1.32(1.24-1.40)$ & $1.64(1.53-1.77)$ \\
\hline 1930s & $1.36(1.32-1.41)$ & $1.26(1.18-1.33)$ & $1.34(1.28-1.41)$ & $1.45(1.38-1.52)$ \\
\hline 1940s & $1.39(1.35-1.44)$ & $1.23(1.15-1.31)$ & $1.30(1.24-1.35)$ & $1.52(1.46-1.59)$ \\
\hline 1970s & $1.26(1.22-1.29)$ & $1.10(0.99-1.22)$ & $1.17(1.11-1.24)$ & $1.30(1.26-1.35)$ \\
\hline 1980s & $1.15(1.12-1.17)$ & $1.20(1.11-1.29)$ & $1.07(1.02-1.12)$ & $1.17(1.14-1.20)$ \\
\hline 1990s & $1.11(1.09-1.14)$ & $1.12(1.04-1.21)$ & $1.10(1.04-1.16)$ & $1.11(1.08-1.15)$ \\
\hline $2000 \mathrm{~s}$ & $1.09(1.05-1.12)$ & $1.07(0.94-1.23)$ & $1.07(0.99-1.15)$ & $1.09(1.05-1.13)$ \\
\hline
\end{tabular}

